\title{
Long-term ERT monitoring of biogeochemical changes of an aged hydrocarbon contamination
}

\author{
David Caterina $^{\mathrm{a}, \mathrm{b}, *}$, Adrian Flores Orozco ${ }^{\mathrm{c}}$, Frédéric Nguyen ${ }^{\mathrm{b}}$ \\ a Institute of Bio and Geosciences 3, Forschungszentrum Jülich, Jülich, Germany \\ b Applied Geophysics Unit, Faculty of Applied Sciences, University of Liège, Liège, Belgium \\ ${ }^{\mathrm{c}}$ Research Group Geophysics, Department of Geodesy and Geoinformation, TU-Wien, Vienna, Austria
}

\begin{abstract}
A B S T R A C T
Adequate management of contaminated sites requires information with improved spatio-temporal resolution, in particular to assess bio-geochemical processes, such as the transformation and degradation of contaminants, precipitation of minerals or changes in groundwater geochemistry occurring during and after remediation procedures. Electrical Resistivity Tomography (ERT), a geophysical method sensitive to pore-fluid and poregeometry properties, permits to gain quasi-continuous information about subsurface properties in real-time and has been consequently widely used for the characterization of hydrocarbon-impacted sediments. However, its application for the long-term monitoring of processes accompanying natural or engineered bioremediation is still difficult due to the poor understanding of the role that biogeochemical processes play in the electrical signatures. For in-situ studies, the task is further complicated by the variable signal-to-noise ratio and the variations of environmental parameters leading to resolution changes in the electrical images. In this work, we present ERT imaging results for data collected over a period of two years on a site affected by a diesel fuel contamination and undergoing bioremediation. We report low electrical resistivity anomalies in areas associated to the highest contaminant concentrations likely due transformations of the contaminant due to microbial activity and accompanying release of metabolic products. We also report large seasonal variations of the bulk electrical resistivity in the contaminated areas in correlation with temperature and groundwater level fluctuations. However, the amplitude of bulk electrical resistivity variations largely exceeds the amplitude expected given existing petrophysical models. Our results suggest that the variations in electrical properties are mainly controlled by microbial activity which in turn depends on soil temperature and hydrogeological conditions. Therefore, ERT can be suggested as a promising tool to track microbial activity during bioremediation even though further research is still needed to completely understand the bio-geochemical processes involved and their impact on electrical signatures.
\end{abstract}

\section{Introduction}

The industrial development, combined with a lack of adequate regulations to protect the environment in the past, has resulted in a large number of contaminated sites, which poses a serious problem for our society (Panagos et al., 2013). Identification and characterization of such sites conventionally rely on the analysis of groundwater and soil samples, thus requiring the drilling of boreholes for sampling. This approach provides concentrations and characteristics of the pollutants, but it only brings sparse information at the field scale. Nevertheless, an adequate management of contaminated sites requires information with improved spatio-temporal resolution, in particular to assess contaminant transformation and degradation during and after remediation.
Hence, there is a growing interest in the application of non-intrusive geophysical methods, which permit to characterize the bulk physical properties of the subsurface to gain information of relevance such as the geometry of contaminant plumes, changes in contaminant concentrations, degradation or transport of pollutants. Considering the sensitivity of electrical methods to pore fluid properties, electrical imaging methods - such as the electrical resistivity tomography (ERT) -, have been largely investigated to improve the characterization of contaminated areas. Imaging results have reported an increase of electrical resistivity due to fresh spills of hydrocarbons (e.g., DeRyck et al., 1993; Benson et al., 1997; Yang et al., 2007); while measurements collected in "aged" hydrocarbon contaminant plumes have reported a decrease of the electrical resistivity over time with respect to the background (e.g.,

\footnotetext{
* Corresponding author at: Institute of Bio and Geosciences 3, Forschungszentrum Jülich, Jülich, Germany.

E-mail address: d.caterina@fz-juelich.de (D. Caterina).
} 
Sauck et al., 1998; Atekwana et al., 2000; Cassidy et al., 2001; Werkema et al., 2003; Che-Alota et al., 2009). The increase in the electrical resistivity in fresh spills clearly reflects the electrical properties of the hydrocarbons as electrical insulators; whereas the decrease in the electrical resistivity is more complex and is attributed to different biogeochemical processes, such as: (i) the stimulation of microbial growth due to the available carbon source; (ii) the increase of total dissolved solids due to the release of organic and carbonic acids as metabolic products by bacteria; (iii) the weathering of minerals and related increase in porosity and salinity (e.g., Sauck et al., 1998; Werkema et al., 2003; Atekwana et al., 2004); (iv) the accumulation of electrical conductive biomass (e.g., Abdel Aal et al., 2004; Davis et al., 2006; Davis et al., 2010; Albrecht et al., 2011), (v) the changes of oil wettability (Revil et al., 2011) and (vi) the precipitation of conductive minerals due to the action of Fe(III)-reducing microorganisms (Flores Orozco et al., 2011, 2013; Revil et al., 2010; Mewafy et al., 2011). For a detailed description of such processes and associated geophysical signatures, we refer to the study of Atekwana and Atekwana (2010) and references therein.

At field scale, only a few studies have addressed the long-term monitoring of biodegradation (or natural attenuation) of hydrocarbons (Che-Alota et al., 2009; Gasperikova et al., 2012; Flores Orozco et al., 2013; Blondel et al., 2014; Heenan et al., 2014; Noel et al., 2016; Ntarlagiannis et al., 2016). In particular, Heenan et al. (2014) reported ERT results for monitoring data collected over a period of 18 months at a fresh spill of hydrocarbons in a highly saline environment. They observed a general decrease in resistivity with time in zones impacted by the contaminants while most of uncontaminated areas only exhibited negligible variations. The resistivity decrease was attributed to the effect of microbial degradation of contaminant mass. The increase in the electrical conductivity following microbial attenuation has also been reported in other field studies (e.g., Flores Orozco et al., 2012a). However, long-term observations of such effects are still scarce and there are still gaps in our understanding of the role that the above biogeochemical processes play in the electrical signatures over time. For in-situ studies, this is further complicated by the variable resolution in the electrical images and variations of environmental parameters.

In this study, we present ERT monitoring results for data collected over 2-years monitoring period conducted at a site impacted by oil leakage in underground tanks. We investigate temporal variations in the electrical signature due to chemical transformation of the contaminants following an engineered bioremediation procedure as well as bio-geochemical processes enhanced due to seasonal fluctuations in the groundwater table and temperature. Particular attention is paid to the adequate data error estimation and image appraisal to permit an unbiased use of electrical models.

\section{Material and methods}

\subsubsection{Site description}

The site is located in the province of Liège (Belgium). It is covered by a concrete/asphalt layer that extends to a depth of approximately $0.2 \mathrm{~m}$ below ground surface (bgs). The latter is underlain by ballasts or backfill deposits ( $\approx 0.8 \mathrm{~m}$ thickness). Underneath the surface cover, we find alluvial deposits (see geological background in Fig. 1) consisting mostly of Quaternary clayey and loamy soils with thin horizons of altered chalks and peat generally associated to clayey loam rich in fossils.

According to sediments recovered during the drilling of a deep well (borehole position indicated as DP in Fig. 1), the thickness of the Quaternary deposits is $7 \mathrm{~m}$. The investigated zone occupies an area of approximately $2000 \mathrm{~m}^{2}$. The site is referred to an oil-spill caused by leakage in buried (or underground) storage tanks, which was initially assessed between 2005 and 2006 through the analysis of groundwater and soil samples by Eurofins Analytico B.V. Such investigations reported that the main contaminated area is located around the two southernmost tanks, which extends approximately over $30 \mathrm{~m}$ (as presented in Fig. 2a, note that contaminant concentrations are expressed as a total hydrocarbon oil index $\mathrm{C}_{10}-\mathrm{C}_{40}$ ) and affects only the backfill and alluvial deposits (i.e., a maximum depth of $7 \mathrm{~m}$ bgs). The groundwater contaminant plume spreads over a slightly larger area than the impacted soil. Two other groundwater contaminant plumes were detected during sampling. The first is located in the northern part of the site (see sampling point FC7 in Fig. 2a) and can probably be attributed to some leaks in the buried 12,000 L diesel tank. The second is located in the western part of the site (see sampling points PZ2 and PZ4 in Fig. 2a). Its origin is unknown but could be related to the presence of another contamination source located north of the site (not shown in Fig. 2a).

The groundwater table at the site was found at a mean depth of $1.62 \mathrm{~m}$ bgs. The minimum and maximum depths were reported during the winter (e.g., $1.25 \mathrm{~m}$ in January 2011) and summer (e.g., $2 \mathrm{~m}$ in August 2012) periods respectively. Measurements in groundwater samples reported a mean electrical conductivity value of $1473 \mu \mathrm{S} / \mathrm{cm}$ and a mean temperature of $11.8{ }^{\circ} \mathrm{C}$. A map of the groundwater flow is presented in Fig. 2a, with the pattern in groundwater flow explained by the presence of a pumping well located $30 \mathrm{~m}$ south of the site (represented as PW in Fig. 1).

Between June 2008 and June 2011, a bioremediation technique, based on aerobic degradation, was conducted at the site to reduce the concentrations of groundwater contaminants. In particular, groundwater was pumped from several wells located in the center of the contaminant plume (see yellow markers in Fig. 2a) and delivered to bioreactor tanks where it was oxygenated by air diffusion and amended with nutrients (i.e., a nitrogen source). After concluded the treatment, water amended with $\mathrm{H}_{2} \mathrm{O}_{2}$ was reinjected into the ground in the fringes of the contaminated zone to further promote the activity of degrading bacteria. $\mathrm{H}_{2} \mathrm{O}_{2}$ has first a bactericidal effect to avoid clogging of the injection wells and then rapidly dissociates to $\mathrm{H}_{2} \mathrm{O}$ and $\mathrm{O}_{2}$, serving as an oxygen source for aerobic bacteria in the subsurface.

During the geochemical characterization in 2005-2006 and during the setup of the bioremediation technique in 2008, several piezometers, screened in the Quaternary deposits, were installed on the site (see blue circumferences in Fig. 2a).

\subsubsection{Electrical resistivity tomography (ERT)}

ERT aims at imaging variations of the bulk electrical resistivity $\rho_{b}$ (or its inverse, the bulk electrical conductivity $\sigma_{b}$, with $\sigma_{b}=\frac{1}{\rho_{b}}$ ) of the subsurface. The interpretation of the resistivity images is often based on the petrophysical relation linking $\rho_{b}$ and porosity $\phi$, fluid electrical conductivity $\sigma_{f}$, groundwater saturation $S_{w}$ and surface electrical conductivity $\sigma_{s}$, following the model proposed by Revil (2013):

$\sigma_{b}=\frac{1}{F} \sigma_{f} S_{w}^{n}+\frac{1}{F \phi} \sigma_{s} S_{w}^{n-1}$

where $F$ is the formation factor and $n$ an empirical value referred to as the saturation exponent. According to Archie (1942), the formation factor can be expressed as:

$F=\frac{1}{\phi^{m}}$

where $m$ is the so-called cementation exponent.

As observed in Eq. 1, the electrical conduction in sediments free of metallic materials is dominated by fluid and surface conduction. Fluid electrical conduction takes place through the electrolyte filling the pore space (ionic conduction), whereas surface conduction takes place at the electrical double layer at the grain-fluid interface (Waxman and Smits, 1968; Revil and Glover, 1998). Surface conduction is often assumed to be relevant only in media containing clay minerals, yet some reserves may need to be considered as some studies (e.g., Revil et al., 2014) have 


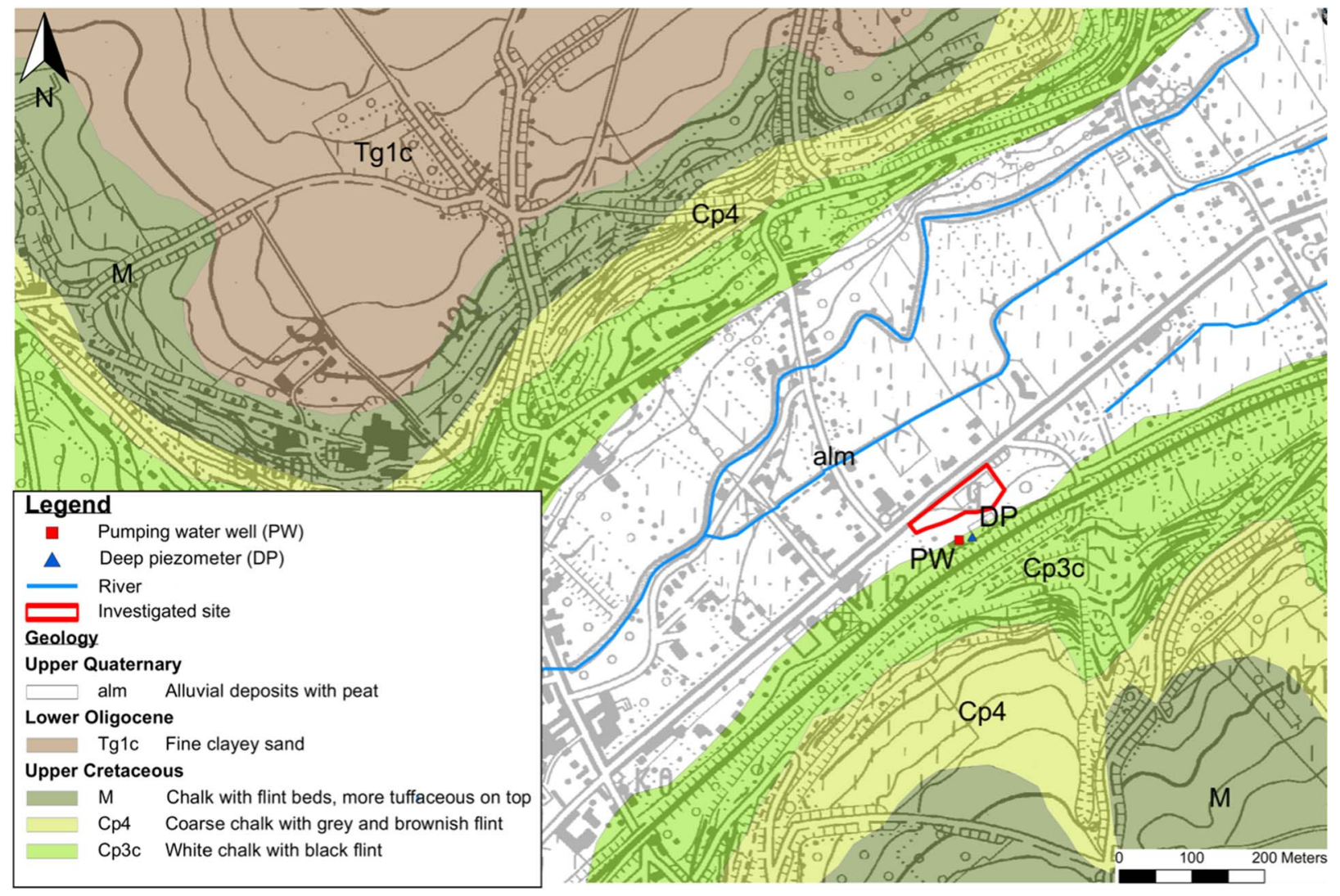

Fig. 1. Localization of the site on a geological background (adapted from Van den Broeck and Forir, 1903).

also reported non-negligible surface conduction in clay-free sandstones.

\subsubsection{Field instrumentation and data acquisition}

For ERT data collection, we used an ABEM Lund Imaging System SAS 1000 ( 1 recording channel, resolution of $1 \mu \mathrm{V}$ at $0.5 \mathrm{~s}$ integration time) from November 2010 to November 2011 and an ABEM Terrameter LS (12 recording channels, resolution of $3 \mathrm{nV}$ at $1 \mathrm{~s}$ integration time) from January 2012 to December 2012. Measurements were collected along one profile (P1 in Fig. 2a) using 48 electrodes with a separation of $1 \mathrm{~m}$ between them (see Fig. 2b), and a Dipole-Dipole configuration (Dahlin and Zhou, 2004). The DipoleDipole sequence deployed has a total of 629 measurements, with a maximum separation between current and potential dipoles limited to $30 \mathrm{~m}$ and a maximum dipole length (for both current and potential dipoles) of $8 \mathrm{~m}$. To enhance the galvanic contact, stainless steel electrodes were installed $40 \mathrm{~cm}$ inside holes drilled through the asphalt layer and filled with salty bentonite.

The location of the profile P1 was designed to gain information about the electrical properties in the subsurface associated with different contaminant concentrations, in particular high contaminant concentrations between 0 and $27 \mathrm{~m}$ along the profile direction. Measurements in P1 were re-collected between December 2010 and December 2012 for monitoring purposes, yielding fourteen different resistivity images: December 2010, March 2011, June 2011, August 2011, September 2011, October 2011, November 2011, January 2012, April 2012, July 2012, August 2012, September 2012, November 2012 and December 2012.

\section{Results}

\subsubsection{Data error analysis}

The resolution of inverted resistivity distribution is highly dependent on an adequate quantification of data noise (LaBrecque et al., 1996). If the actual data noise is underestimated, imaging results may reveal the presence of numerical artifacts. Inversely, if the actual data noise is overestimated, imaging results may be affected by a loss of resolution. Therefore, a reliable assessment of the data error is critical to solve for electrical images with enhanced resolution and quantitative meaning (Flores Orozco et al., 2012b). LaBrecque et al. (1996) suggested to introduce the data error $(e)$ as a function of the measured transfer resistance $(R)$ in the inversion of ERT datasets. Slater et al. (2000) proposed a linear model of the type:

$|e|=a+b \times R$

where $a$ is the absolute error (expressed in $\Omega$ ) and $b$ is the relative error (expressed in \%). Note that such error model takes into account only random errors, inherit to any measurements, characterized by a Gaussian distribution. Correlated errors are associated to systematic sources of errors, such as poor contact between the electrodes and the soil, disconnected or damaged cables, etc. For an adequate estimation of random data-error, measurements revealing systematic errors need to be removed first as outliers.

To assess the quality of collected data, we repeated each one of the 14 monitoring measurements at least 2 times. Analysis of the data was performed for each independent data: we discarded outliers defined as those measurements associated with negative resistances and variations larger than $3 \%$ in our repetitivity test. To avoid the comparison of monitoring datasets associated with a different number of independent quadrupoles (i.e., configurations that were measured in all monitoring 

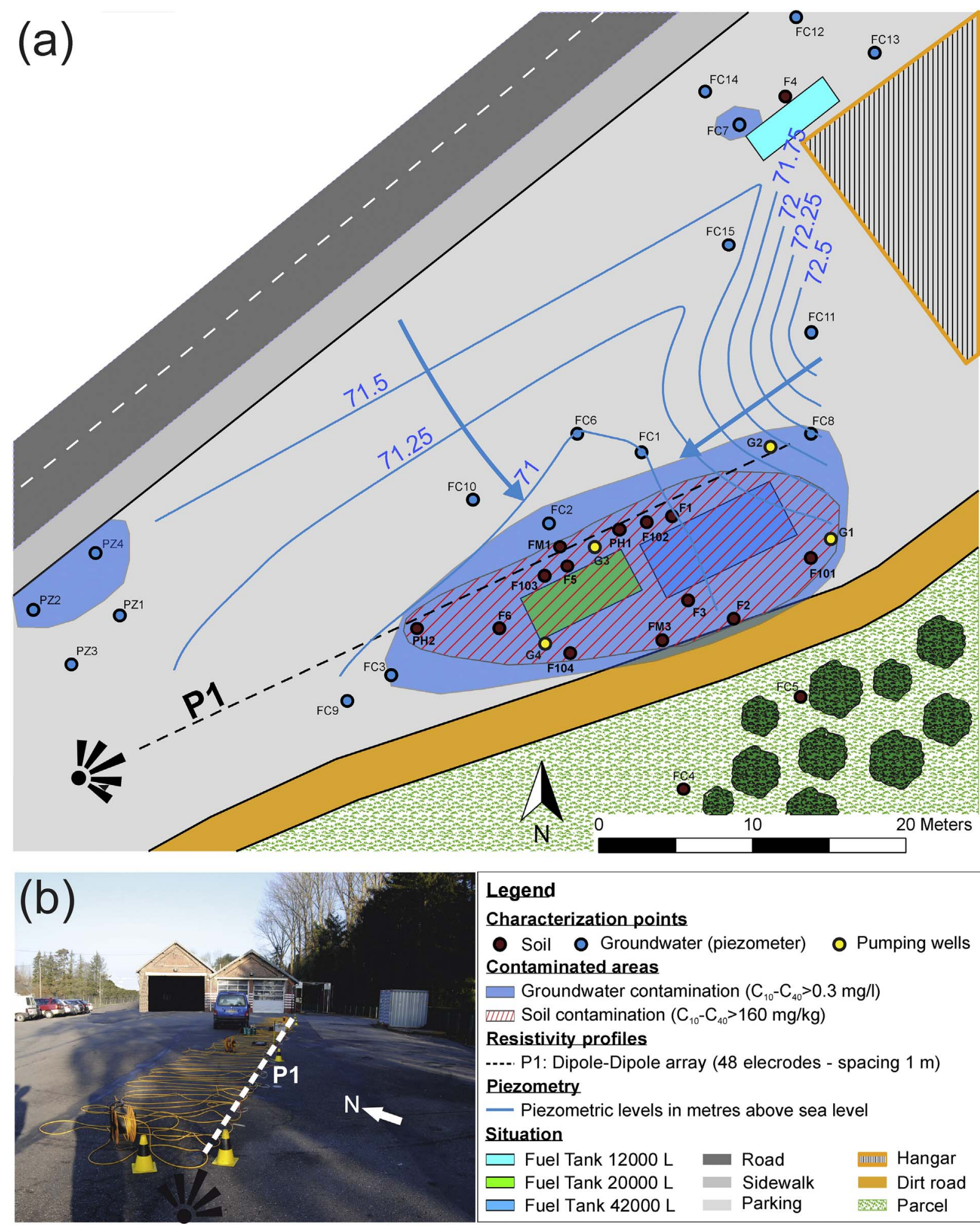

Legend

Characterization points

- Soil o Groundwater (piezometer) o Pumping wells Contaminated areas

$\square$ Groundwater contamination $\left(\mathrm{C}_{10}-\mathrm{C}_{40}>0.3 \mathrm{mg} / \mathrm{l}\right)$

UIII Soil contamination $\left(\mathrm{C}_{10}-\mathrm{C}_{40}>160 \mathrm{mg} / \mathrm{kg}\right)$

Resistivity profiles

-.-. P1: Dipole-Dipole array (48 elecrodes - spacing $1 \mathrm{~m}$ )

Piezometry

- Piezometric levels in metres above sea level

Situation

$\square$ Fuel Tank 12000

$\square$ Fuel Tank $20000 \mathrm{~L}$

Fuel Tank $42000 \mathrm{~L}$

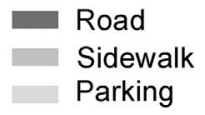

Hangar
Dirt road
Parcel

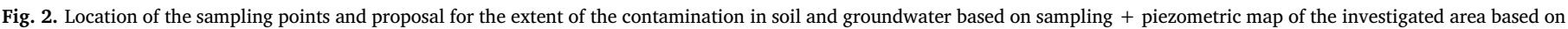
groundwater levels measured in September 2011 + location of the ERT profile P1 (a), picture of the site with the setup of the ERT profile (b).

measurements), inversion was performed with datasets containing only quadrupoles common to all monitoring datasets (428 out of the 629 readings).

To estimate data-error, we collected several reciprocal measurements, where reciprocal refers to the re-collection of the data after interchanging current and potential electrodes. The analysis of the misfit between normal and reciprocal readings is a widely accepted technique to quantify error parameters in Eq. 3 (e.g., LaBrecque et al., 1996; Slater et al., 2000; Slater and Binley, 2006; Koestel et al., 2008; Flores Orozco et al., 2012b). For our study, we computed error models for each dataset based on the bin-analysis of the misfit between normal and reciprocal readings as proposed by Koestel et al. (2008). Variations in the error parameters for the different monitoring datasets can be observed in Fig. 3. The relative error (b) is almost constant over time; 


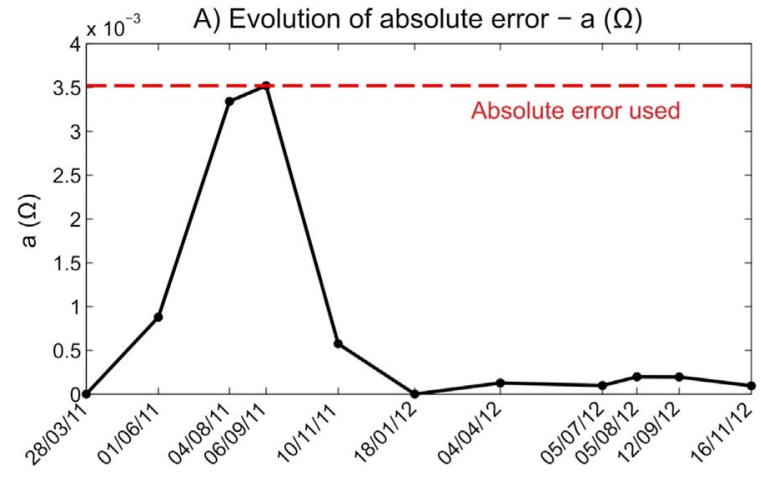

B) Evolution of relative error $-b$

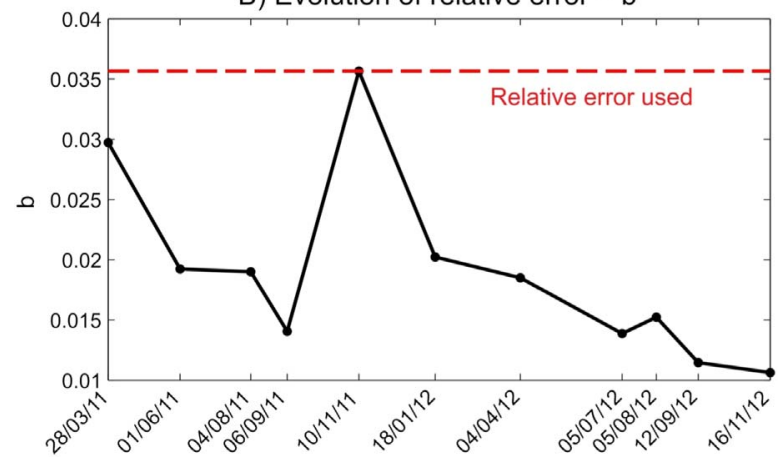

Fig. 3. Evolution in function of time of coefficients $-\mathrm{a}$ and $\mathrm{b}$ - of fitted error model: $|e|=a+b \times R$

whereas the absolute error (a) is particularly high in the datasets collected in 2011, likely due to a lower resolution and/or precision in the measuring device. To permit a fair comparison in the electrical images, we inverted all monitoring datasets to the same error level determined by the highest error parameters found in the independent analysis. We opted for this alternative to minimize the risk of solving for artifacts in the images due to an under-estimation of data error (i.e., overfitting the data within the inversion). Hence, all monitoring datasets were fitted to the same error-level, namely an absolute error of $3.5 \mathrm{~m} \Omega$ and a relative error of $3.57 \%$, giving an error model which can be written as:

$|e|=3.5 \times 10^{-3}+0.0357 \times R$

\subsubsection{Inversion procedure}

Inversion schemes which rigorously minimize the data misfit, rather than minimizing a model objective function subject to fitting the data to a pre-defined uncertainty (as it is done in this work), always bear the risk of over-fitting the data and thus creating artifacts in the images. Hence, inversion of our data was performed with the smoothnessconstraint algorithm CRTomo by Kemna (2000), which permits the incorporation of the error parameters in the inversion. Here, at each iteration step of the inversion, a univariate search is performed to find the optimum value of the regularization parameter which locally minimizes the data misfit. The iteration process is stopped when the root mean square of the error weighted data-misfit $(\varepsilon R M S)$ reaches the value of one. In detail, the $\varepsilon R M S$ is written as:

$\varepsilon R M S=\sqrt{\frac{\sum_{i=1}^{N}\left(d_{o b s}-d_{\text {calc }}\right)^{2}}{N}}$

where $d_{o b s}$ is the observed data, $d_{c a l c}$ is the calculated data through forward modelling and $N$ is the number of data. The mesh used for the inversion is composed of finite-elements with a size of $0.5 \times 0.5 \mathrm{~m}$. We used a standard constraint on the data $\left(\mathrm{L}_{2}\right.$ norm) and a smoothness constraint on the model for the inversion. For all monitoring images, we used the same starting model, corresponding to the image obtained in December 2010.

Two approaches were considered to invert our datasets: individual and time-lapse inversions. The first consists in inverting each individual dataset separately using the inversion scheme detailed above. The major drawback of such approach is that it may lead to misinterpretation when analyzing changes between models that do not present the same resolution. The risk of misinterpretation may be reduced by inverting data corresponding to quadrupole configuration common to all datasets with the same error model and using the same starting model. The second approach, proposed by Daily et al. (1992) and Labrecque and Yang (2000), consists in inverting the data difference rather than the individual dataset. Such approach, used for instance in Revil et al. (2013), is referred to time-lapse inversion. It may allow reducing the effect of systematic errors present in the data that cancel out by subtraction and obtaining models that are constrained by the background solution. However, Flores Orozco et al. (2011) demonstrated that proper data-error quantification was enough to solve for quantitative changes in the electrical images, even in the lack of a timeregularization. In our case, with measurements collected with a rather long time-gap and under different hydrogeological conditions, and with different instruments, temporal regularization is not expected to significantly improve the results. Therefore, the individual inversion approach was preferred.

A common issue for a quantitative interpretation of imaging results is the reliability of inverted parameters. Several tools have been developed to investigate the image appraisal in electrical resistivity tomography, such as the sensitivity uncertainty (e.g., Kemna, 2000; Nguyen et al., 2009; Beaujean et al., 2014; Hermans et al., 2015), the Depth of Investigation Index - DOI (e.g., Oldenburg and Li, 1999; Marescot et al., 2003; Robert et al., 2011), and the resolution matrix (e.g., Friedel, 2003; Oldenborger and Routh, 2009; Caterina et al., 2013).

In this study, we assess the reliability of our imaging results using the DOI, which can be defined as the depth below which the model parameters are not constrained by the data anymore (Oldenburg and Li, 1999) but by the reference model. The computation of DOI requires running two inversions of the same dataset that only differ by the damped reference model used. The comparison of both inversion results permits to investigate the effect due to variations in the reference model (for a detailed revision, we refer to Oldenburg and Li, 1999). DOI maps are normally composed of values ranging between 0 and 1 , with values close to zero for model parameters in the inverted model still constrained by the surface data; whereas DOI values close to one means that the reference model is progressively mapped into the resulting image. The transition from low to high DOI values occurs generally in a relatively narrow range which allows the selection of a threshold value which defines the data-constrained area in the electrical images for interpretation. In our study, we opted for a threshold value defined as the maximum gradient of the DOI, which was found in our inversion results at a maximum depth of $7 \mathrm{~m}$ (to the center of the profile), as it can be observed in Fig. 4 for the inversion of the baseline measurements (December 2010).

\subsubsection{Baseline measurements (December 2010)}

Imaging results for profile P1 collected for the baseline of the monitoring are presented in Fig. 4. Lithological information, as obtained from wellbore data, is added to the electrical image to facilitate the interpretation of the electrical units. Fig. 4 permits to distinguish two main areas related to contrasting electrical properties: (i) on one hand, in the western part of P1 (from 30 to $47 \mathrm{~m}$ along the profile direction), the asphalt and backfills deposits are defined by a layer characterized by high resistivity values ( $>40 \Omega \cdot \mathrm{m}$ ) on top of conductive materials $(<20 \Omega \cdot \mathrm{m})$, which corresponds to the clayey loams characteristic of the site; (ii) on the other hand, electrical properties of the contaminated area (between 10 and $28 \mathrm{~m}$ along the 

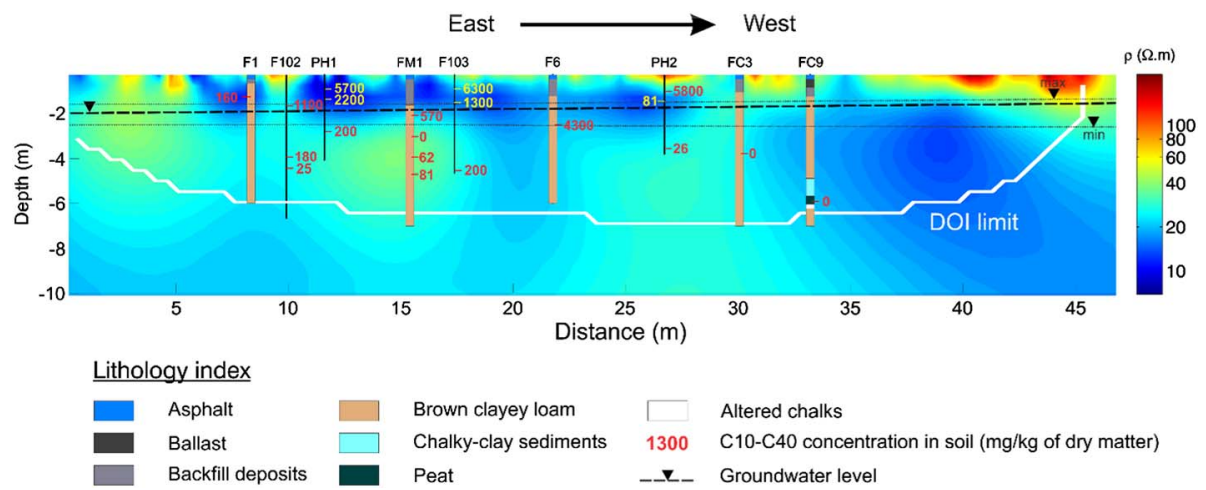

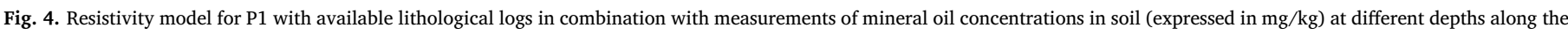

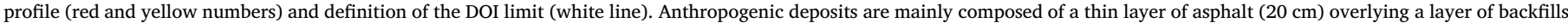

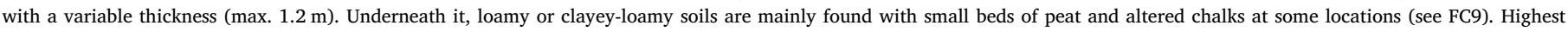

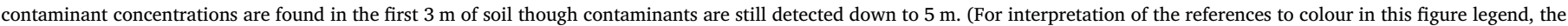
reader is referred to the web version of this article.)

profile direction) reveal the opposite pattern, with low resistivity values $(\sim 10 \Omega \cdot \mathrm{m})$ associated to the asphalt and backfill materials, and slightly higher resistivity values for the clayey loams (20-40 $\Omega \cdot \mathrm{m})$; such area is also related to the highest hydrocarbon concentrations reported (up to $6300 \mathrm{mg} / \mathrm{kg}$ in soils samples, as indicated in Fig. 4).

In the contaminated area mapped by P1 ( 1 to $25 \mathrm{~m}$ along profile direction), it is also possible to delineate a few anomalies characterized by higher resistivity values (approximately 40-60 $\Omega \cdot \mathrm{m}$ ) at depths between 3 and $6 \mathrm{~m}$ bgs, with such anomalies not found in the western section of P1 (in clean sediments).

\subsubsection{Seasonal monitoring 2010-2012}

Resistivity changes occur throughout the monitoring in all areas of P1 (Fig. 5), with significant variations particularly observed in the contaminated anomalies described above (between 3 and $6 \mathrm{~m} \mathrm{bgs}$ ).

To quantitatively investigate temporal changes in the electrical properties, we extracted model parameters from the electrical images at four different locations (indicated by black crosses and circles in Fig. 5). Such voxels represent four different areas along the profile direction associated with different contaminant concentrations. Their evolution over time, expressed in percentage of resistivity change compared to baseline measurements, is shown in Fig. 6. Plots of the electrical resistivity for voxels extracted from the contaminated area, at a depth of $3.75 \mathrm{~m}$ bgs, reveal a periodic pattern: electrical resistivity values show an important decrease ( $>40 \%$ ) from December 2010 to August 2011, which then increase until January $2012(+40 \%)$, when they decrease again until July $2012(-30 \%)$ and then increase again from July 2012 to December $2012(+20 \%)$. Variations are periodical, with slightly lower resistivity changes in 2012 than in 2011. Resistivity values extracted at $1.75 \mathrm{~m}$ bgs, also in the contaminated area, reveal similar periodical fluctuations but for lower magnitudes (maximum changes of $\sim 20 \%$ ), which are also slightly reduced in 2012. In contrast, resistivity values extracted from the uncontaminated area reveal minimal variations over time and no periodical fluctuations. Large changes of electrical resistivity observed in depth between 0 and $2 \mathrm{~m}$ bgs are mostly related to seasonal changes in the saturation of the backfill materials and will not be further discussed.

\section{Discussion}

\subsubsection{December 2010: baseline measurements}

To explain the low electrical resistivity observed in the most contaminated area, we argue that the release of metabolic products increases the salinity (i.e., fluid conductivity). Hydrocarbons likely act as electron donors, enhancing bacterial activity; thus, promoting the release of organic and carbonic acids, which in turn enhances the weathering of grains and increases the electrical conductivity of the electrolyte, as described in detail in Abdel Aal et al. (2006) and discussed by Atekwana and Atekwana (2010) taking into account observations from different studies (e.g. Sauck et al., 1998; Atekwana et al., 2000; Bradford, 2007; Cassidy, 2008). Furthermore, biomass accumulation may also lead to the increase in the electrical conductivity due to surface conduction along the membrane of microbial cells or biofilm (Revil et al., 2012). Furthermore, recent studies have demonstrated the stimulation of iron reducers in aged hydrocarbon plumes, promoting the precipitation of metallic minerals (Mewafy et al., 2011); thus modifying the electrical response of impacted sediments due to enhanced electronic conduction. To investigate the presence of such metallic minerals in the contaminated area, we drilled a hole down to a depth of $4.4 \mathrm{~m}$ at the distance of $20 \mathrm{~m}$ along P1 and collected 5 soil samples representing different depth intervals (see Table 1).

We then measured the mass magnetic susceptibility of each sample using a Kappabridge KLY-3 susceptibility meter (AGICO Corporation, Brno, Czech Republic, operating frequency of $875 \mathrm{~Hz}$ ). Results are illustrated in the Fig. 7a. For each data presented, we made the measurement on 5 subsamples to assess the variability of $\mathscr{X}_{\text {mass }}$ at each depth interval. Sample no 1 is characterized with higher $\mathscr{X}_{\text {mass }}$ $\left(6.9 \times 10^{-6} \mathrm{~m}^{3} \mathrm{~kg}^{-1}\right)$ compared to the underneath samples. The mean values of samples no 2,3 and 4 are in the same order of magnitude (respectively $1.9 \times 10^{-7}, 3 \times 10^{-7}$ and $2.2 \times 10^{-7} \mathrm{~m}^{3} \mathrm{~kg}^{-1}$ ) while the value of sample no 5 is one order of magnitude lower $\left(3.1 \times 10^{-8} \mathrm{~m}^{3} \mathrm{~kg}^{-1}\right)$.

We analyzed the percentage of material retained by a bar magnet to determine the proportion of iron-rich material in each depth interval. Backfill deposits (sample no 1 ) contain up to $25 \%$ of magnetic minerals, while the underneath samples contain $<1 \%$. Although zones of active iron-reduction are difficult to identify with certainty (due to the low vertical sampling resolution, the high variability of mass magnetic susceptibility measurements and the masking effect of the backfill layer with high content of magnetic material), they are however suspected for samples no 3 and no 4 that lay within the hydrocarbon smear zone induced by groundwater table fluctuations (see Fig. 7b).

The presence of contaminants in concentrations ranging from 25 to $200 \mathrm{mg} / \mathrm{kg}$ (see boreholes F102, PH1, FM1, F103 and PH2 in Fig. 2a and Fig. 4) suggests that resistive anomalies observed at depths between 3 and $6 \mathrm{~m}$ in the contaminated area are related to the presence of hydrocarbon contaminants but with reduced or minimal biodegradation (i.e., negligible release of carbonic acids). Hence, such anomalies may be interpreted as source-zones associated with trapped hydrocarbons in phase, underlying the increase in the electrical resistivity, as observed in previous studies (e.g., Atekwana et al., 2002). The leakage of hydrocarbons from buried tanks and historical depths in the ground- 
Initial model
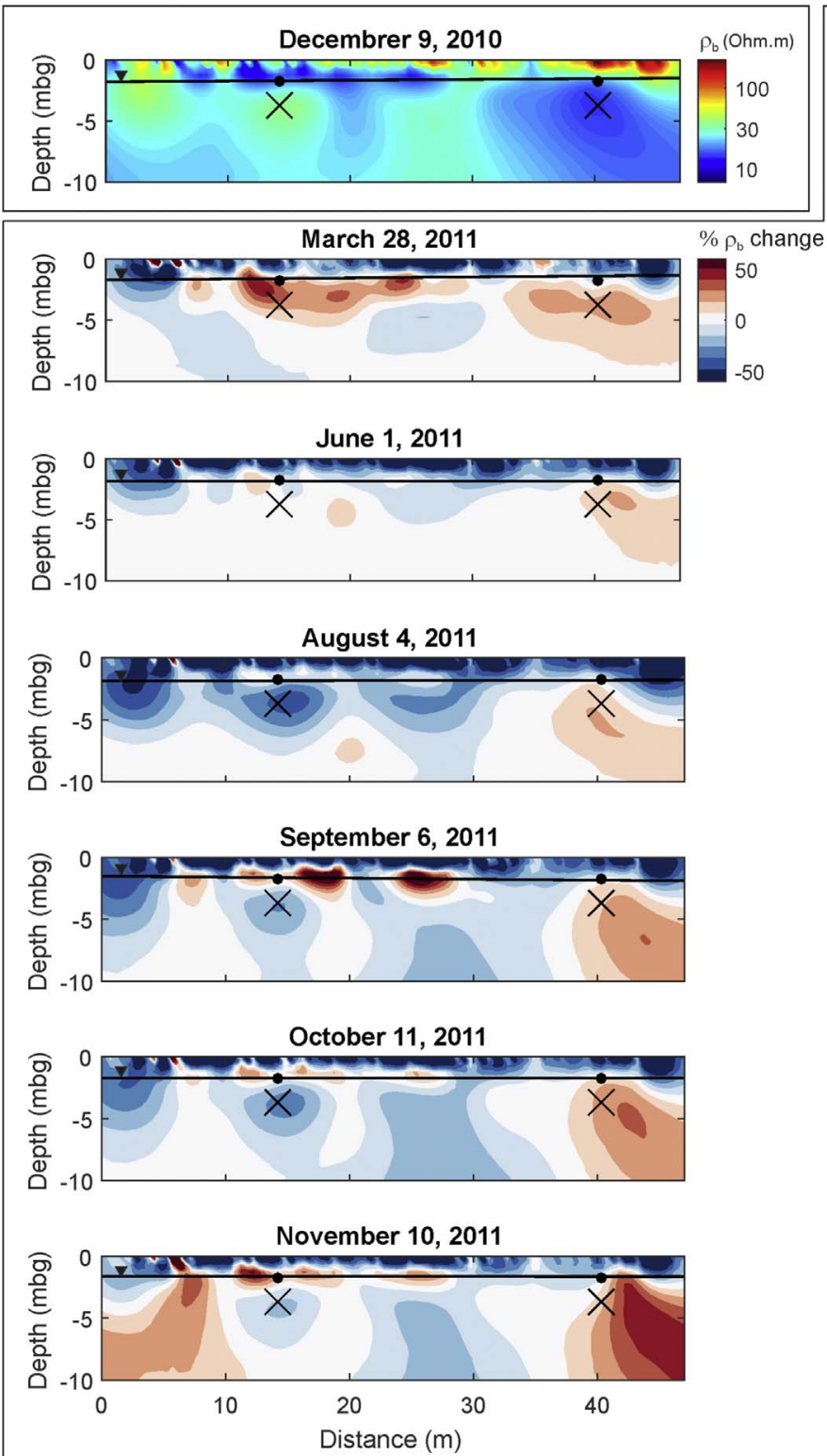

\section{$\%$ of $\rho_{b}$ change compared to the initial model}
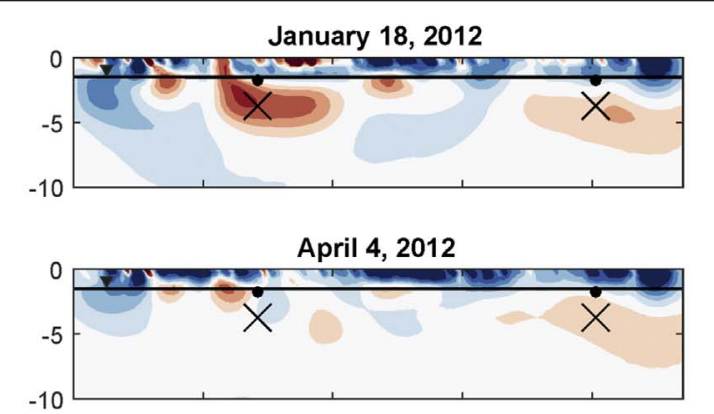

July 5, 2012

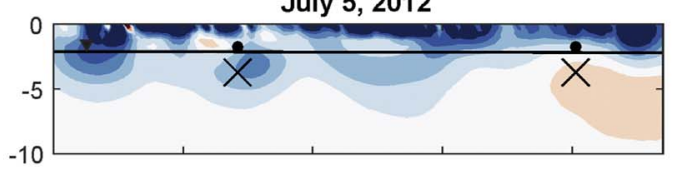

August 10, 2012
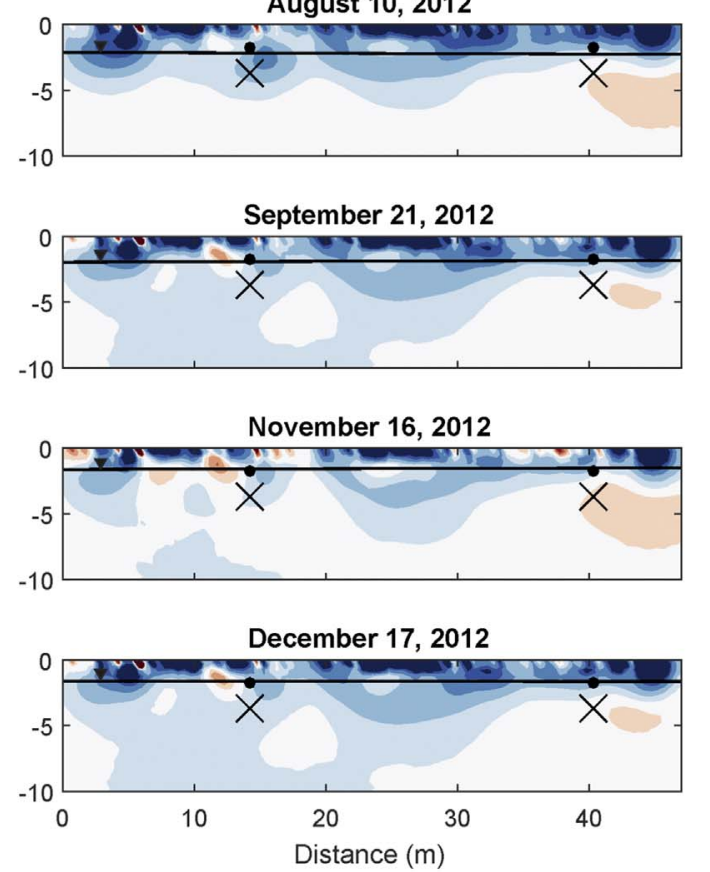

$X$ and $\quad=$ Parameters selected to illustrate the evolution of resistivity with time (see Figure 7)

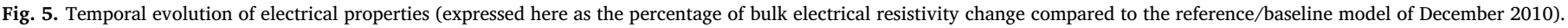
Model parameters were extracted for quantitative analysis at the locations indicated by the black crosses and black circles.

water level (levels down to $4 \mathrm{~m}$ bgs were, for instance, reported in summer 2008) can explain the transport of free-phase contaminants to $5 \mathrm{~m}$ depth, as observed in P1. The application of the bioremediation to the source zone is in line with our interpretation of the resistive anomalies observed in P1.

\subsubsection{Seasonal monitoring}

The periodic changes observed in the resistivity values for the contaminated area follow the trend of seasonal temperature variations (Fig. 6c), as well as from groundwater level fluctuations (Fig. 6d), suggesting that both influence the resistivity variations. Bulk electrical conductivity increases with temperature (Revil et al., 1998; Hayley et al., 2007; Hermans et al., 2014). Temperature influences both $\sigma_{f}$ (via fluid viscosity and ionic mobility) and $\sigma_{s}$ (via surface ionic mobility). According to Revil et al. (1998), $\sigma_{f}$ and $\sigma_{s}$ increase linearly with increasing temperature. We calculated the fractional change in $\sigma_{f}$ per degree Celsius from a water sample collected in FM1 (see location in
Fig. 2a and Fig. 4) and found a value of $0.0197^{\circ} \mathrm{C}^{-1}$. Hayley et al. (2007) found, for similar materials, a value of the fractional change in surface ionic mobility (directly affecting surface conductivity) per degree Celsius equals to $0.018{ }^{\circ} \mathrm{C}^{-1}$. Both $\sigma_{f}$ and $\sigma_{s}$ vary in the same range with temperature. Consequently, approximately $2 \%$ of $\sigma_{b}$ change per degree Celsius is expected at the site.

Air temperature variations (Fig. 6c) reveal a consistent pattern with the periodical changes observed in the electrical resistivity values for pixels extracted from the contaminated region of $\mathrm{P} 1$, which also reflects the seasonal variations observed in groundwater table. During the biostimulation phase (from June 2008 to July 2011), the temperature of groundwater coming from the pumping wells was monitored. Seasonal variations between $7{ }^{\circ} \mathrm{C}$ and $21{ }^{\circ} \mathrm{C}$ were reported (Fig. 8a) suggesting that air temperature still directly affects soil temperature at depth below $2 \mathrm{~m}$. Variations in electrical conductivity measured in groundwater samples (Fig. 8d) also reveal consistent seasonal variations with groundwater temperature. Nevertheless, the plot in Fig. 8d 

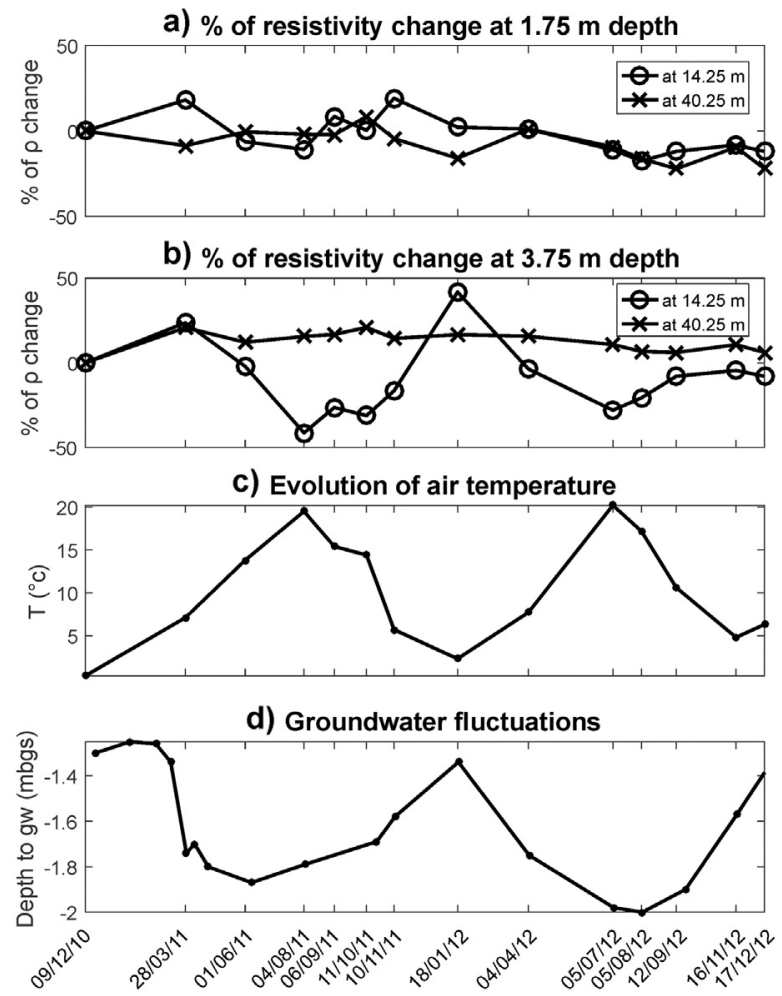

Fig. 6. Percentage of bulk electrical resistivity change compared to the reference/ baseline measurements (December 2010) for pixel values extracted in the contaminated (14.25 m, horizontal distance) and in the uncontaminated (40.25 m, horizontal distance) areas at respectively $1.75 \mathrm{~m}$ (a) and $3.75 \mathrm{~m}$ (b) depth + evolution of air temperatures observed at a meteorological station located $5 \mathrm{~km}$ southwest of the site (c) + Groundwater fluctuations expressed in meters below ground surface (d).

Table 1

Description of samples collected at a distance of $20 \mathrm{~m}$ along P1.

\begin{tabular}{lll}
\hline Sample no & Depth interval (m) & Lithology \\
\hline 1 & 0 to 1.2 & Backfill deposits \\
2 & 1.2 to 2 & Alluvial deposits \\
3 & 2 to 3 & \\
4 & 3 to 3.2 & \\
5 & 3.2 to 4.4 & \\
\hline
\end{tabular}

shows some scattering along the monitoring period, likely related to variations in the samples. Analysis of the temporal variations in other geochemical parameters such as pH (Fig. 8b), dissolved oxygen (Fig. 8c) and nitrate concentrations (Fig. 8e) reveal only a poor correlation with the change observed in the electrical resistivity.

We provide in Fig. 9 soil temperature data collected with a distributed temperature sensor (AP Sensing Linear Pro Series N4386, $10 \mathrm{~cm}$ resolution) in September 2012 and November 2012 in two piezometers (F103 in Fig. 9a and FC3 in Fig. 9b) located along the profile direction. From the data provided, it is clear that the influence of air temperature on soil temperature is still significant at least down to $4 \mathrm{~m}$ bgs.

To illustrate the maximum possible influence of temperature on electrical properties, we computed the estimated changes in the electrical resistivity due to air temperature variations (see dashed curve in Fig. 10) using the following petrophysical model and assuming a fractional change of $\sigma_{b}$ per degree Celsius of $2 \%$.

$\sigma_{b, \text { estimated }}=\sigma_{b, \text { Dec2010 }} \times\left(0.02 \times\left(T-T_{D e c 2010}\right)+1\right)$

where $\sigma_{b, \text { estimated }}$ is the estimated bulk electrical conductivity at the date of interest, $\sigma_{b, D e c 2010}$ is the bulk electrical conductivity extracted from the baseline model, $T$ is the air temperature at the date of interest, and $T_{\text {Dec2010 }}$ is the baseline air temperature.

The solid curve (Fig. 10) presents the evolution of model parameters (i.e., electrical resistivity) extracted from the contaminated region at $3.75 \mathrm{~m}$ bgs. Although both curves reveal a consistent evolution over time, there are clear discrepancies in the magnitude, in particular for the winter periods. Thus, it is clear that the only effect of temperature on fluid viscosity and ionic mobility cannot explain the changes in the electrical resistivity. However, temperature is also known to control bacterial activity and growth in the sense that a higher temperature generally results in a higher enzymatic activity (Alvarez and Illman, 2006). For instance, Blume et al. (2002) showed that for an increase of soil temperature from 3 to $20^{\circ} \mathrm{C}$, the microbial activity in soil could increase by $83 \%$. Furthermore, an increase in temperature also enhances the solubility of hydrocarbons. An increase in the microbial activity will directly lead to the release of carbonic acids. Hence, it is possible to explain seasonal variations in the electrical resistivity as a clear indication of microbial activity, which is promoted at higher temperatures and is indirectly stimulated by a larger availability of carbon sources (due to the higher solubility of hydrocarbon at higher temperatures). Thus, winter periods, associated to shallow depths to the groundwater table and lower temperatures, are clearly correlated to a decrease in the electrical resistivity due to the decrease in temperature, lower hydrocarbon solubility and the transport of free-phase from deeper horizons.

In combination with the effect of temperature, we believe that fluctuations in groundwater (see Fig. 6d) also influence the electrical resistivity by controlling the microbial activity taking place at the site, in particular, the switch between aerobic and anaerobic conditions, which in turn controls geochemical changes in groundwater associated to changes in redox-conditions, accumulation of biomass, the release of metabolic products as well as groundwater temperature variations (e.g., Warren and Bekins, 2015).

Hence, it is possible to confirm that periodic variations in the electrical properties of hydrocarbon-impacted sediments are related to geochemical changes in the subsurface mainly induced by microbial activity which is in turn controlled by seasonal changes in the soil temperature and the depth to groundwater table.
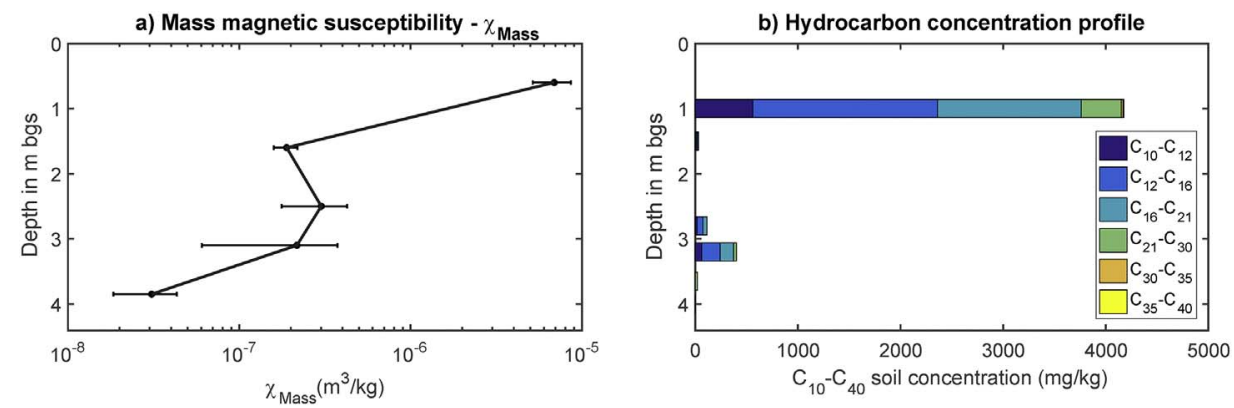

Fig. 7. Results of tests carried out on the samples collected at $20 \mathrm{~m}$ along P1 with (a) mass magnetic susceptibility and (b) mineral oil concentration in soil in function of depth. 
a) Water temperature $\left({ }^{\circ} \mathrm{C}\right)$

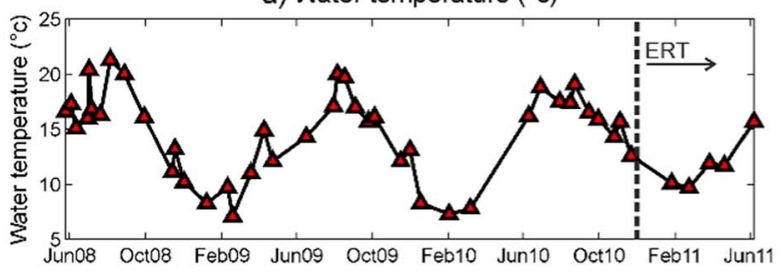

c) Dissolved $\mathrm{O}_{2}(\mathrm{mg} / \mathrm{l})$

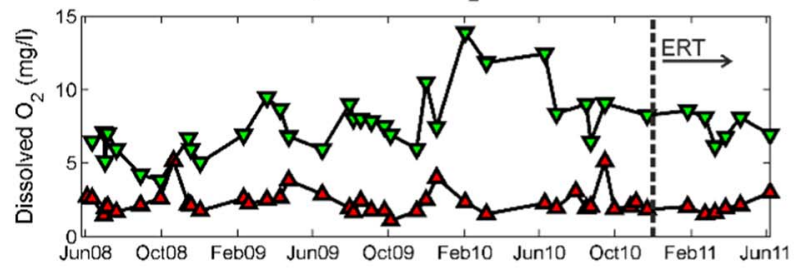

b) $\mathrm{pH}$

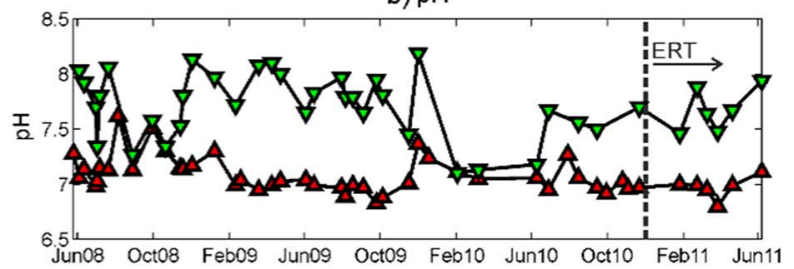

d) Water conductivity ( $\mu \mathrm{S} / \mathrm{cm})$

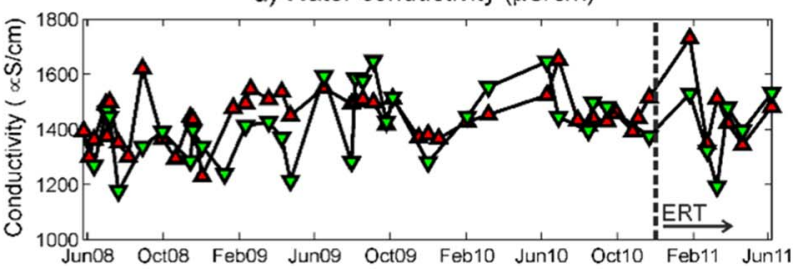

e) $\mathrm{NO}_{3}$ concentration $(\mathrm{mg} / \mathrm{l})$

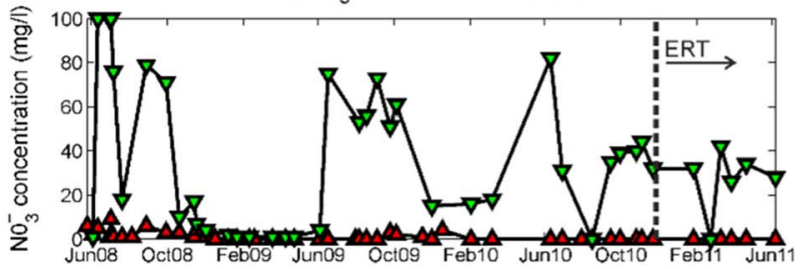

$\Delta$ - Pumped water

$\rightarrow$-Injected water

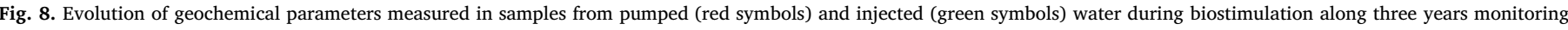

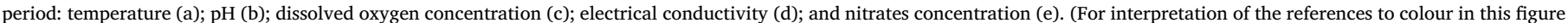
legend, the reader is referred to the web version of this article.)

a) F103 piezometer

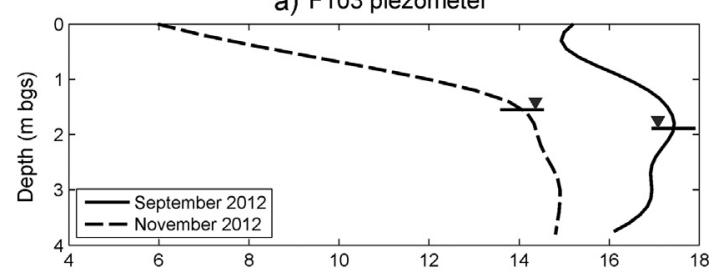

b) FC3 piezometer

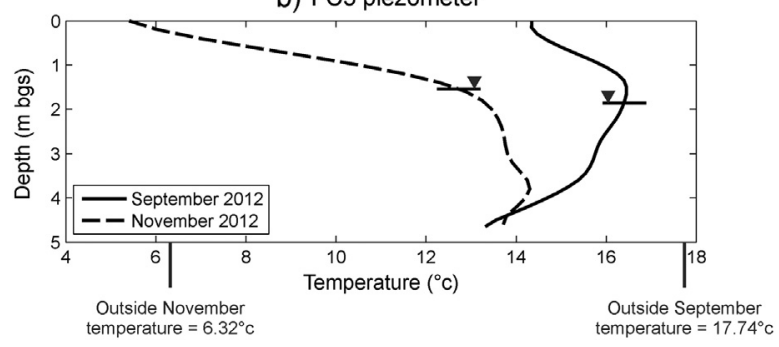

Fig. 9. Soil temperature collected in two piezometers - F103 (a) and FC3 (b)- located along the ERT profile (see Fig. 2a) in September and November 2012.

\section{Conclusions}

We applied ERT monitoring to investigate bio-geochemical changes in the bulk electrical resistivity in a site impacted by the leakage of underground diesel fuel storage tanks. ERT data were collected over a monitoring period of two years following three years of biostimulation (pump and treat, nutrient addition $\&$ reinjection). Our results reveal that the most contaminated areas above the groundwater table level are associated to low resistivity $(<10 \Omega \cdot \mathrm{m})$, likely due to microbial transformations of the oil contaminants and in particular to the release of carbonic acids, biomass accumulation and bioprecipitation of conductive minerals, as it has been observed in numerous studies. Below the groundwater level, we report resistive anomalies in clayey sedi-
Actual vs expected (given $\mathrm{T}^{\circ}$ ) percentage of $\rho_{b}$ change at $3.75 \mathrm{~m}$

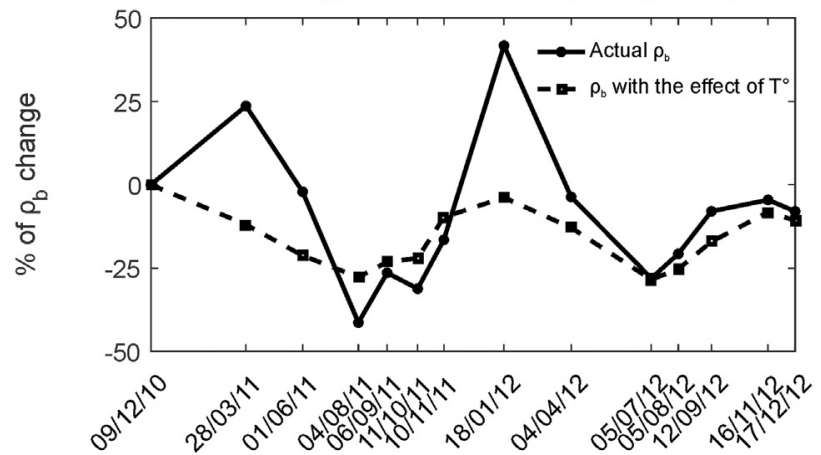

Fig. 10. Comparison between the actual electrical resistivity variations at $3.75 \mathrm{~m}$ depth and at a horizontal distance of $14.25 \mathrm{~m}$, and the variations of electrical resistivity at the same location assuming only the effect of temperature.

ments associated to trapped hydrocarbons below the groundwater level that do not undergo active biodegradation. Our results reveal seasonal variations of the bulk electrical resistivity in the contaminated areas correlated to seasonal fluctuations in the depth of the groundwater table and temperature. In agreement with existing petrophysical models, electrical resistivity in our monitoring images decreases during the summer periods (lower temperatures) and increases in winter.

Computed changes in the electrical resistivity, based on the temperature variations, cannot fully explain the variations observed. Thus, it is possible to conclude that variations in the bulk electrical resistivity are controlled by microbial activity (release of metabolic products such as carbonic acids and biomass accumulation among other processes), which in turn is strongly influenced by seasonal variations. However, further research is needed to completely understand the biogeochemical processes taking place in hydrocarbon contaminated areas and the associated electrical signatures.

Future works performed at the field scale should involve the more 
frequent acquisition of electrical measurements to further capture the dynamic of microbial activity. In addition, electrical measurements should include induced polarization (IP) data that may provide a clearer picture of the effects associated with the presence of hydrocarbons, as evidenced by Flores Orozco et al. (2012a) and Flores Orozco et al. (2015), and spontaneous potential (SP) data that are sensitive to redox conditions and may therefore reveal areas of active biodegradation (e.g., Naudet et al., 2004). For the inversion, the application of spatio-temporal regularization schemes (e.g., Karaoulis et al., 2011) could be particularly relevant and interesting to explore. Similarly to Sihota et al. (2016), the collection of soil temperature, soil volume water content, precipitation data and $\mathrm{CO}_{2}$ effluxes is also recommended. Finally, as a complement to the field measurements, the collection of soil samples to study petrophysics (e.g., Revil et al., 2011) or microbial processes (e.g., Masy et al., 2016) in laboratory would be also be helpful for the interpretation of field data.

\section{Acknowledgment}

This work was supported by the Belgian National Fund for Scientific Research (FRIA-FNRS) which attributed two grants (No. 5002810F and $5209211 F)$ to D. Caterina. The authors thank also Sanifox for their collaboration in this research and the supply of material and expertise.

\section{References}

Aal, G.Z.A., Slater, L.D., Atekwana, E.A., 2006. Induced-polarization measurements on unconsolidated sediments from a site of active hydrocarbon biodegradation. Geophysics 71 (2), H13-H24.

Abdel Aal, G.Z., Atekwana, E.A., Slater, L.D., Atekwana, E.A., 2004. Effects of microbial processes on electrolytic and interfacial electrical properties of unconsolidated sediments. Geophys. Res. Lett. 31 (12), L12505.

Albrecht, R., Gourry, J.C., Simonnot, M.-O., Leyval, C., 2011. Complex conductivity response to microbial growth and biofilm formation on phenanthrene spiked medium. J. Appl. Geophys. 75 (3), 558-564.

Alvarez, P.J.J., Illman, W.A., 2006. Bioremediation and natural attenuation: process fundamentals and mathematical models. In: Environmental Science and Technology. John Wiley \& Sons, Hoboken, New Jersey, USA (609 pp.).

Archie, G.E., 1942. The electrical resistivity log as an aid in determining some reservoir characteristics. Trans. Americ. Inst. Mineral. Met. 146, 54-62.

Atekwana, E.A., Atekwana, E.A., 2010. Geophysical signatures of microbial activity at hydrocarbon contaminated sites: a review. Surv. Geophys. 31 (2), 247-283.

Atekwana, E.A., Sauck, W.A., Werkema, D.D., 2000. Investigations of geoelectrical signatures at a hydrocarbon contaminated site. J. Appl. Geophys. 44 (2-3), 167-180.

Atekwana, E.A., Sauck, W.A., Aal, G.Z.A., Dale Werkema, D., J., 2002. Geophysical investigation of vadose zone conductivity anomalies at a hydrocarbon contaminated site: implications for the assessment of intrinsic bioremediation. J. Environ. Eng. Geophys. 7 (3), 103-110.

Atekwana, E.A., Atekwana, E.A., Werkema, D.D., Allen, J.P., Smart, L.A., Duris, J.W., Cassidy, D.P., Sauck, W.A., Rossbach, S., 2004. Evidence for microbial enhanced electrical conductivity in hydrocarbon-contaminated sediments. Geophys. Res. Lett. 31 (23), L23501.

Beaujean, J., Nguyen, F., Kemna, A., Antonsson, A., Engesgaard, P., 2014. Calibration of seawater intrusion models: Inverse parameter estimation using surface electrical resistivity tomography and borehole data. Water Resour. Res. 50 (8), 6828-6849.

Benson, A.K., Payne, K.L., Stubben, M.A., 1997. Mapping groundwater contamination using dc resistivity and VLF geophysical methods-a case study. Geophysics 62 (1), $80-86$.

Blondel, A., Schmutz, M., Franceschi, M., Tichané, F., Carles, M., 2014. Temporal evolution of the geoelectrical response on a hydrocarbon contaminated site. J. Appl. Geophys. 103, 161-171.

Blume, E., Bischoff, M., Reichert, J.M., Moorman, T., Konopka, A., Turco, R.F., 2002. Surface and subsurface microbial biomass, community structure and metabolic activity as a function of soil depth and season. Appl. Soil Ecol. 20 (3), 171-181.

Bradford, J.H., 2007. Frequency-dependent attenuation analysis of ground-penetrating radar data. Geophysics 72 (3), J7-J16.

Cassidy, N.J., 2008. GPR attenuation and scattering in a mature hydrocarbon spill: a modeling study. Vadose Zone J. 7 (1), 140-159.

Cassidy, D.P., Werkema, J.D.D., Sauck, W., Atekwana, E., Rossbach, S., Duris, J., 2001 The effects of LNAPL biodegradation products on electrical conductivity measurements. J. Environ. Eng. Geophys. 6 (1), 47-52.

Caterina, D., Beaujean, J., Robert, T., Nguyen, F., 2013. A comparison study of different image appraisal tools for electrical resistivity tomography. Near Surface Geophysics 11 (6), 639-657.

Che-Alota, V., Atekwana, E.A., Atekwana, E.A., Sauck, W.A., Dale Werkema, D., J., 2009. Temporal geophysical signatures from contaminant-mass remediation. Geophysics 74 (4), B113-B123.

Dahlin, T., Zhou, B., 2004. A numerical comparison of 2D resistivity imaging with 10 electrode arrays. Geophys. Prospect. 52, 379-398.

Daily, W., Ramirez, A., LaBrecque, D., Nitao, J., 1992. Electrical resistivity tomography of vadose water movement. Water Resour. Res. 28 (5), 1429-1442.

Davis, C.A., Atekwana, E., Atekwana, E., Slater, L.D., Rossbach, S., Mormile, M.R., 2006. Microbial growth and biofilm formation in geologic media is detected with complex conductivity measurements. Geophys. Res. Lett. 33 (18), L18403.

Davis, C.A., Pyrak-Nolte, L.J., Atekwana, E.A., Werkema, D.D., Haugen, M.E., 2010 Acoustic and electrical property changes due to microbial growth and biofilm formation in porous media. J. Geophys. Res. Biogeosci. 115 (G3), G00G06.

DeRyck, S.M., Redman, J.D., Annan, A.P., 1993. Geophysical monitoring of a controlled kerosene spill. In: 6th EEGS Symposium on the Application of Geophysics to Engineering and Environmental Problems (SAGEEP), San Diego, pp. 5-19.

Flores Orozco, A., Williams, K.H., Long, P.E., Hubbard, S.S., Kemna, A., 2011. Using complex resistivity imaging to infer biogeochemical processes associated with bioremediation of an uranium-contaminated aquifer. J. Geophy. Res. Biogeosci. 116 (G3) (n/a-n/a).

Flores Orozco, A., Kemna, A., Oberdörster, C., Zschornack, L., Leven, C., Dietrich, P., Weiss, H., 2012a. Delineation of subsurface hydrocarbon contamination at a former hydrogenation plant using spectral induced polarization imaging. J. Contam. Hydrol. 136-137 (0), 131-144.

Flores Orozco, A., Kemna, A., Zimmermann, E., 2012b. Data error quantification in spectral induced polarization imaging. Geophysics 77 (3), E227-E237.

Flores Orozco, A., Williams, K.H., Kemna, A., 2013. Time-lapse spectral induced polarization imaging of stimulated uranium bioremediation. Near Surface Geophysics 11 (5), 531-544.

Flores Orozco, A., Velimirovic, M., Tosco, T., Kemna, A., Sapion, H., Klaas, N., Sethi, R., Bastiaens, L., 2015. Monitoring the injection of microscale zerovalent iron particles for groundwater remediation by means of complex electrical conductivity imaging. Environ. Sci. Technol. 49 (9), 5593-5600.

Friedel, S., 2003. Resolution, stability and efficiency of resistivity tomography estimated from a generalized inverse approach. Geophys. J. Int. 153 (2), 305-316.

Gasperikova, E., Hubbard, S.S., Watson, D.B., Baker, G.S., Peterson, J.E., Kowalsky, M.B., Smith, M., Brooks, S., 2012. Long-term electrical resistivity monitoring of rechargeinduced contaminant plume behavior. J. Contam. Hydrol. 142, 33-49.

Hayley, K., Bentley, L.R., Gharibi, M., Nightingale, M., 2007. Low temperature dependence of electrical resistivity: implications for near surface geophysical monitoring. Geophys. Res. Lett. 34 (18), L18402.

Heenan, J., Slater, L.D., Ntarlagiannis, D., Atekwana, E.A., Fathepure, B.Z., Dalvi, S., Ross, C., Werkema, D.D., Atekwana, E.A., 2014. Electrical resistivity imaging for long-term autonomous monitoring of hydrocarbon degradation: Lessons from the Deepwater Horizon oil spill. Geophysics 80 (1), B1-B11.

Hermans, T., Nguyen, F., Robert, T., Revil, A., 2014. Geophysical methods for monitoring temperature changes in shallow low enthalpy geothermal systems. Energies 7 (8), 5083-5118.

Hermans, T., Wildemeersch, S., Jamin, P., Orban, P., Brouyère, S., Dassargues, A., Nguyen, F., 2015. Quantitative temperature monitoring of a heat tracing experiment using cross-borehole ERT. Geothermics 53, 14-26.

Karaoulis, M., Revil, A., Werkema, D., Minsley, B., Woodruff, W., Kemna, A., 2011. Timelapse three-dimensional inversion of complex conductivity data using an active time constrained (ATC) approach. Geophys. J. Int. 187 (1), 237-251.

Kemna, A., 2000. Tomographic Inversion of Complex Resistivity: Theory and Application. Der Andere Verlag, Osnabrück.

Koestel, J., Kemna, A., Javaux, M., Binley, A., Vereecken, H., 2008. Quantitative imaging of solute transport in an unsaturated and undisturbed soil monolith with 3-D ERT and TDR. Water Resour. Res. 44 (12), W12411.

Labrecque, D., Yang, X., 2000. Difference inversion of ERT data: a fast inversion method for 3-D in-situ monitoring. In: E.E.G. Society (Ed.), 13th EEGS Symposium on the Application of Geophysics to Engineering and Environmental Problems, pp. 723-732.

LaBrecque, D.J., Miletto, M., Daily, W., Ramirez, A., Owen, E., 1996. The effects of noise on Occam's inversion of resistivity tomography data. Geophysics 61 (2), 538-548.

Marescot, L., Loke, M.H., Chapellier, D., Delaloye, R., Lambiel, C., Reynard, N., 2003. Assessing reliability of $2 \mathrm{D}$ electrical resistivity imaging in mountain permafrost studies using the depth of investigation index method. Near Surface Geophysics 1, 57-67.

Masy, T., Caterina, D., Tromme, O., Lavigne, B., Thonart, P., Hiligsmann, S., Nguyen, F., 2016. Electrical resistivity tomography to monitor enhanced biodegradation of hydrocarbons with Rhodococcus erythropolis T902.1 at a pilot scale. J. Contam. Hydrol. 184, 1-13.

Mewafy, F.M., Atekwana, E.A., Werkema, D.D., Slater, L.D., Ntarlagiannis, D., Revil, A., Skold, M., Delin, G.N., 2011. Magnetic susceptibility as a proxy for investigating microbially mediated iron reduction. Geophys. Res. Lett. 38 (21), L21402.

Naudet, V., Revil, A., Rizzo, E., Bottero, J.-Y., Bégassat, P., 2004. Groundwater redox conditions and conductivity in a contaminant plume from geoelectrical investigations. Hydrol. Earth Syst. Sci. 8 (1), 8-22.

Nguyen, F., Kemna, A., Antonsson, A., Engesgaard, P., Kuras, O., Ogilvy, R., Gisbert, J., Jorreto, S., Pulido-Bosch, A., 2009. Characterization of seawater intrusion using 2D electrical imaging. Near Surf. Geophys. 7 (5), 377-390 October 2009.

Noel, C., Gourry, J.-C., Deparis, J., Blessing, M., Ignatiadis, I., Guimbaud, C., 2016. Combining geoelectrical measurements and CO2 analyses to monitor the enhanced bioremediation of hydrocarbon-contaminated soils: a field implementation. Appl. Environ. Soil Sci. 2016.

Ntarlagiannis, D., Robinson, J., Soupios, P., Slater, L., 2016. Field-scale electrical geophysics over an olive oil mill waste deposition site: Evaluating the information content of resistivity versus induced polarization (IP) images for delineating the spatial extent of organic contamination. J. Appl. Geophys. 135, 418-426.

Oldenborger, G.A., Routh, P.S., 2009. The point-spread function measure of resolution for 
the 3-D electrical resistivity experiment. Geophys. J. Int. 176 (2), 405-414.

Oldenburg, D.W., Li, Y., 1999. Estimating depth of investigation in dc resistivity and IP surveys. Geophysics 64 (2), 403-416.

Panagos, P., Van Liedekerke, M., Yigini, Y., Montanarella, L., 2013. Contaminated sites in Europe: review of the current situation based on data collected through a European network. J. Environ. Public Health 2013.

Revil, A., 2013. Effective conductivity and permittivity of unsaturated porous materials in the frequency range $1 \mathrm{mHz}-1 \mathrm{GHz}$. Water Resour. Res. 49 (1), 306-327.

Revil, A., Glover, P.W.J., 1998. Nature of surface electrical conductivity in natural sands, sandstones, and clays. Geophys. Res. Lett. 25 (5), 691-694.

Revil, A., Cathles, L.M., Losh, S., Nunn, J.A., 1998. Electrical conductivity in shaly sands with geophysical applications. J. Geophys. Res. Solid Earth 103 (B10), 23925-23936.

Revil, A., Mendonça, C.A., Atekwana, E.A., Kulessa, B., Hubbard, S.S., Bohlen, K.J., 2010. Understanding biogeobatteries: where geophysics meets microbiology. J. Geophys. Res. Biogeosci. 115 (G1), G00G02.

Revil, A., Schmutz, M., Batzle, M.L., 2011. Influence of oil wettability upon spectral induced polarization of oil-bearing sands. Geophysics 76 (5), A31-A36.

Revil, A., Atekwana, E., Zhang, C., Jardani, A., Smith, S., 2012. A new model for the spectral induced polarization signature of bacterial growth in porous media. Water Resour. Res. 48 (9), W09545.

Revil, A., Skold, M., Karaoulis, M., Schmutz, M., Hubbard, S.S., Mehlhorn, T.L., Watson, D.B., 2013. Hydrogeophysical investigations of the former S-3 ponds contaminant plumes, Oak Ridge Integrated Field Research Challenge site, Tennessee. Geophysics 78 (4), EN29-EN41.

Revil, A., Kessouri, P., Torres-Verdín, C., 2014. Electrical conductivity, induced polarization, and permeability of the Fontainebleau sandstone. Geophysics 79 (5), D301-D318.
Robert, T., Dassargues, A., Brouyère, S., Kaufmann, O., Hallet, V., Nguyen, F., 2011. Assessing the contribution of electrical resistivity tomography (ERT) and selfpotential (SP) methods for a water well drilling program in fractured/karstified limestones. J. Appl. Geophys. 75 (1), 42-53.

Sauck, W.A., Atekwana, E.A., Nash, M.S., 1998. High conductivities associated with an LNAPL plume imaged by integrated geophysical techniques. J. Environ. Eng. Geophys. 2-3, 203-212.

Sihota, N., Trost, J., Bekins, B., Berg, A., Delin, G., Mason, B., Warren, E., Mayer, K., 2016. Seasonal variability in vadose zone biodegradation at a crude oil pipeline rupture site. Vadose Zone J. 15 (5).

Slater, L., Binley, A., 2006. Synthetic and field-based electrical imaging of a zerovalent iron barrier: Implications for monitoring long-term barrier performance. Geophysics 71 (5), B129-B137.

Slater, L., Binley, A.M., Daily, W., Johnson, R., 2000. Cross-hole electrical imaging of a controlled saline tracer injection. J. Appl. Geophys. 44 (2-3), 85-102.

Van den Broeck, E., Forir, H., 1903. In: Belgique, S.G.D. (Ed.), Carte géologique de Belgique, Planchette 107- Tongres-Herderen, 1/40000,

Warren, E., Bekins, B.A., 2015. Relating subsurface temperature changes to microbial activity at a crude oil-contaminated site. J. Contam. Hydrol. 182, 183-193.

Waxman, M.H., Smits, L.J.M., 1968. Electrical conductivities in oil-bearing shaly sands. Soc. Pet. Eng. J. 8 (2), 107-122.

Werkema Jr., D.D., Atekwana, E.A., Endres, A.L., Sauck, W.A., Cassidy, D.P., 2003. Investigating the geoelectrical response of hydrocarbon contamination undergoing biodegradation. Geophys. Res. Lett. 30.

Yang, C.H., Yu, C.Y., Su, S.W., 2007. High resistivities associated with a newly formed LNAPL plume imaged by geoelectric techniques - a case study. J. Chin. Inst. Eng. 30 (1), 53-62. 